\title{
440 - Dementia villages: rethinking dementia care
}

Catarina Pedro ${ }^{1}$, Mariana Duarte ${ }^{2}$, Beatriz Jorge ${ }^{3}$, Daniela Freitas ${ }^{4}$

1 Hospital de Braga, Psychiatry Department, Braga, Portugal. e-mail: catarinap_fernandes@hotmail.com

2 Hospital de Beja, Psychiatry Department, Beja, Portugal. e-mail: mariana_mangas@hotmail.com

3 Hospital de Braga, Psychiatry Department, Braga, Portugal. e-mail: bea.negocios@gmail.com

4 Hospital de Braga, Psychiatry Department, Braga, Portugal. e-mail: danielafreitas84@gmail.com

Introduction: Over the past 20 to 30 years, alternative dementia care models have been developed. Dementia villages challenge popular perceptions about life with dementia and contrast to the traditional model of long-term care facilities that are often seen as institutional, impersonal, and risk-averse. The first dementia village, De Hogeweyk, was developed in 2009 and is located in Weesp, Netherlands. Hogeweyk aims to create a safe environment, enabling the person with dementia to live an "ordinary life" with as much autonomy as possible and also maintaining integration with the local community. Other dementia villages have been established in several countries, following De Hogeweyk model.

Objectives: The aim of this presentation is to describe the functioning of dementia villages and evaluate its benefits on dementia patients.

Methods: A non-systematic review of the literature was performed on PubMed, PsycINFO and Web of science using selected keywords. We also consult the official websites of the institutions.

Results: Dementia villages seem to improve functioning and reduce the need for medication. Anxiety, restlessness and homesickness can still persist, but are reduced by the homelike and hospitable setting in which residents live. In fact, antipsychotic medication use at the residence has decreased from approximately $50 \%$ of residents, before the dementia village was introduced, to approximately $12 \%$ in 2019 . The staff also reported greater job satisfaction. Although dementia villages are growing throughout the Western world, this concept has also been criticized, arguing that this type of living is dishonest, misleading the residents to believe that they are still living in the 'real community'.

Conclusions: Dementia villages are guided by the principles "deinstitutionalize, transform and normalize" care for people with advanced dementia. Although its intuitive advantages, there is no research evidence to demonstrate that this environment has any beneficial effect in behaviour, functional ability or cognition. In future studies, clinical outcomes could be used as a measure of quality of care. Hogeweyk concept has made societies rethinking dementia care and has been inspiring the development of other innovative models of dementia care.

Key-words: dementia, dementia-friendly community, dementia villages, De Hogeweyk 